\title{
POMZA AGREGALI KÖPÜK BETONLARIN ÖZELLİKLERİNİN ARAŞTIRILMASI
}

\author{
Şemsettin KILINÇARSLAN ${ }^{*}$, Metin DAVRAZ² ${ }^{2}$ Mehmet AKÇA ${ }^{1}$
}

${ }^{1}$ Süleyman Demirel Üniversitesi, İnşaat Mühendisliği Bölümü, Isparta

${ }^{2}$ Süleyman Demirel Üniversitesi, Doğal ve Endüstriyel Yapı Malzemeleri Araştırma ve Uygulama Merkezi, Isparta

\begin{tabular}{ll}
\hline Anahtar Kelimeler & Öz \\
\hline Pomza, & Volkanik faaliyetler sonucu oluşan pomza, gözenekli ve içeriğinde kristal suyu yer \\
Köpük Beton, & almayan bir kayaçtır. Gözenekli olması sebebiyle kullanıldığı alanlarda, ısı ve ses \\
Basınç Dayanımı, & geçirgenliği yönünden avantaj sağlamaktadır. Ayrıca gözenekli olduğu için de \\
Isı İletkenlik, & hafiftir. Pomzanın hafif olması, ısı ve ses yalıtım özelliklerinin iyi olması nedeniyle \\
& inşaat sektöründe çeşitli yapı malzemelerinin üretiminde kullanım alanı \\
& bulmaktadır. Buna rağmen, pomzanın inşaat sektöründe yaygın kullanılan \\
& geleneksel yapı malzemelerine göre kullanım oranı oldukça azdır. Bunun \\
& sebeplerinden biri ise ülkemizde bulunan bu doğal kaynakla ilgili yeterli akademik \\
& çalışmaların olmamasıdır. Çalışma kapsamında; Isparta, Kayseri, Nevşehir ve \\
& Karaman pomzaları kullanılarak köpük betonlar üretilmiştir. Kuru birim \\
& yoğunlukları aynı, pomza kökenleri farklı olan köpükbetonların basınç dayanımı, ısı \\
& iletkenlik katsayısı, ses yutma katsayısı ve ses iletim kaybı değerleri değişimleri \\
& incelenmiştir. Pomza kökeninin bu değerler üzerinde farklılı gösterdiği \\
& gözlenmiștir.
\end{tabular}

INVESTIGATION OF PROPERTIES OF FOAM CONCRETE WITH PUMICE

\section{Keywords}

Pumice,

Foam Concrete,

Compressive Strength,

Thermal Conductivity,

\begin{abstract}
Pumice is a porous rock, which is formed as a result of volcanic activity and does not include any crystal water. Its porous structure makes it light-weight and provides advantage for heat and sound isolation. For these reasons, it is widely used in manufacturing of various materials in construction industry. However, compared to other materials used in construction industry, usage of pumice is relatively low. One of the major reasons for low usage of pumice is the fact that there are not enough researches on this natural resource of our country. In this study, pumice aggregates were collected from Isparta region, Kayseri region, Nevșehir region and Karaman region for foam concrete with pumice. The compressive strength, sound transmission loss values, coefficient of thermal conductivity and sound absorption of foamed concrete with the same dry unit densities and different pumice origins have been examined. It has been observed that the pumice origin has a different effect on these values.
\end{abstract}

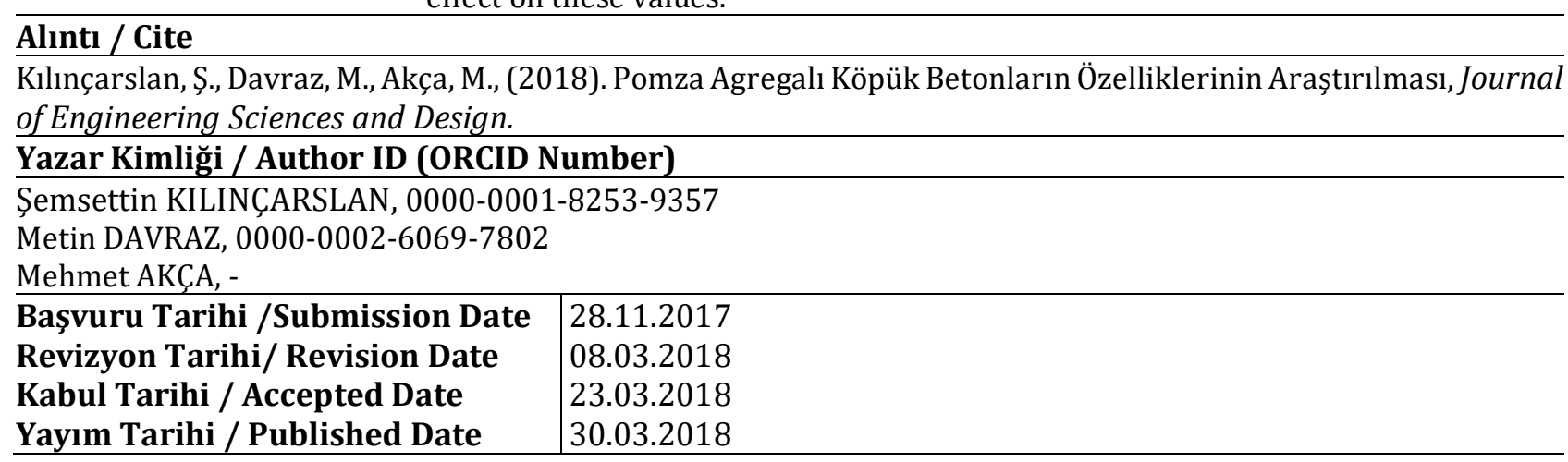

\footnotetext{
* ilgili yazar / Corresponding author: semsettinkilincarslan@sdu.edu.tr, +90-246-211-1206
} 


\section{Giriș}

Beton, inşaat işlerinde çok yaygın kullanım alanı bulan bir yapı malzemesidir. Beton karıșımı temel olarak çimento, su, agrega ve üretilecek betonun amacına uygun katkı maddeleri içerir (Eriç, 2002). Betonun, harca istenilen şeklin verilebilmesi, iskeletini teşkil eden agreganın kolayca temin edilebilmesi, istenilen boyutta yekpare parçaların yapilabilmesi, mukavemetinin fazla oluşu nedeniyle yapı elemanı boyutlarının küçültülebilmesi, işçiliğinin bir ihtisaslaşmaya lüzumu olmayışı gibi avantajlı tarafları bulunmaktadır. Buna karşılık, yüksek ısıya dayanamaması, gerekli tedbirlerin alınmamasıyla ısıyı ve rutubeti geçirmesi, sökülüp tekrar kullanılma imkanından mahrum oluşu ve tamirinin zor veya olanaksız oluşu da betonun dezavantajlarıdır (Uluata, 1981).

Betonun dezavantajları; değişik agrega kullanılarak, katkı maddeleri eklenerek, bileşimi değiştirip yalnızca normal agrega ve çimento kullanarak, yapım tekniğinde değişiklik yaparak ya da bu yöntemlerden birkaçı birlikte kullanılarak özel betonlar üretilmiştir (Baradan, 1991). Geleneksel betonun sahip olduğu dezavantajlara çözümler aranırken, başvurulan yollardan biri de değişik yöntemler kullanılarak betonun birim hacim kütlesini azaltmak olmuştur. Yapılarda kullanılan normal betonun birim hacim kütlesini düşürerek betonarme elemanın öz ağırlıkları azaltılabilir ve böylelikle yapı hafifletilebilir. Yapının hafiflemesi ile taşıyıcı sistem elemanlarının kesitleri küçültülerek ekonomi sağlanabilir (Konuk vd., 2002).

Özel betonların en önemlisi hafif betondur. Hafif beton, genellikle boşluklu, daha düşük yoğunluğa ve dayanıma, daha yüksek ısı yalıtımı özelliklerine sahip olan, bununla birlikte normal betonla aynı amaçlarla kullanılabilen betondur (Neville, 1975). Yoğunluğu $2000 \mathrm{~kg} / \mathrm{m}^{3}$ 'ten düşük hafif betonlar üretmek için çeşitli yöntemler vardır. Birinci yol, beton agregasının ince kısmı çıkarılır. Kaba agrega parçalarını bir arada tutmak için ince harç tabakasıyla kaplamak amacıyla çimento kullanılır. Büyük boşluklu yalıtılmış noktalardan birbirleriyle temas halinde olan parçalar yoğunluğu düşürür. Bu tür betonlar, kumsuz betonlar olarak bilinir. Diğer bir yol ise, kimyasal katkılar veya mekanik köpükleme tekniği kullanılarak betonun içerisinde hava baloncukları oluşturmaktır. Bu tür betonlar havalı, hücreli, köpük ya da gaz beton olarak bilinir. Hafif beton üretmede en yaygın yol ise, hafif agrega kullanmaktır (Neville ve Brooks, 1987).

Günümüzde hafif agregalı beton üretiminde yaygın olarak kullanılan doğal hafif agregalardan biri de pomzadır. Pomza, volkanizma faaliyetleri sırasında yüksek sıcaklık ve basınç altında eriyik halde bulunan magmanın, yeryüzünden atmosferin üst katmanlarına doğru püskürmesiyle ani olarak soğuması ve bünyesindeki gazların uzaklaşması neticesinde kristalleşmeye firsat bulamadığı için çok gözenekli bir yapıya kavuşan piroklastik bir kayaçtır. Pomzanın, düşük birim hacim kütlesi, yüksek ısı ve ses izolasyonu, iklimlendirme özelliği, kolay sıva tutması, mükemmel akustik özelliği, deprem yük ve davranışları karşısındaki elastikiyeti ve alternatiflerine göre daha ekonomik olması gibi üstün özelliklerinden dolayı inşaat ve yapı endüstrisinde geniş bir kullanım alanı bulmaktadır (Davraz, 2001).

Köpük beton ise, hafif betonun bir türüdür ve gözenekli veya hücreli beton olarak da bilinir. Çimento, su ve agreganın karışımından oluşan harca köpük ajanı ile oluşturulan köpügün eklenmesi ile elde edilir. Bünyesinde hacminin \%75-\%80'i oranında birbirinden bağımsız kapalı gözenekler vardır. Köpük beton; tüm binaların iç ve dış duvarları ile zeminlerinde kullanılan yapı elemanlarının yerine kullanılabilecek, bileşiminde doğal agrega ve çimento dışında malzeme bulundurmayan, insan sağlığına zararı olmayan, hafif, ısı ve ses yalıtımı sağlayan, alternatif bir yapı ve yalıtım malzemesidir (Ekinci, 2013).

Köpük beton; taze halde düşük viskoziteye, düşük yoğunluğa, kullanım alanına bağlı olarak yeterli dayanıma ve düşük ısı iletkenlik özelliklerine sahiptir. Genel olarak kuru yoğunluğu 400-1600 kg/m³ , basınç dayanımı 1-15 $\mathrm{MPa}$ aralığındadır. Köpük beton kolayca pompalanabilir ve yerleştirilebilir. Sıkıștırma ve vibrasyon gerektirmez. Suya, dona ve yangına karşı son derece yüksek bir dayanıma sahiptir. Köpük beton harcl, işletmelerde kalıplanıp blok haline getirilebileceği gibi, gerektiğinde mobil olarak uygulama alanında hazırlanarak bir pompa yardımı ile kolayca taşınabilir. Köpük beton, yoğunluğuna bağlı olarak duvar blokları, asmolen, panel, yalıtım tesviye betonu, prefabrik yapı elemanları üretiminde kullanılabilir (Davraz vd., 2015).

Türkiye'nin değişik yörelerinde farklı karakteristik özelliklere sahip birçok pomza türü mevcuttur. Buna rağmen, farklı türde pomza agregasından elde edilen köpük betonların teknik özellikleri üzerine henüz yeterli düzeyde inceleme, analiz ve araștırma yapılmamıștır. $\mathrm{Bu}$ çalışma; ülkemizde potansiyeli yüksek olan ve farklı karakteristik özellikler gösteren Isparta, Nevşehir, Kayseri ve Karaman pomzaları kullanılarak köpük beton üretiminde agrega olarak kullanımını, pomzadan elde edilen köpük betonların yoğunluk, basınç dayanımı, ısı iletkenlik katsayısı, ses 
yutma katsayısı ve ses iletim kaybı değerlerinin belirlenmesi ve bu deneysel çalışmaların sonuçlarının yorumlanmasını kapsamaktadır.

\section{Materyal ve Metot}

Çalışma kapsamında Isparta-Karakaya, Kayseri, Nevşehir ve Karaman yörelerine ait pomza (P) hafif agregaları kullanılarak köpük betonlar üretilmiştir. Ayrıca üretilen köpük betonların özelliklerinin karşılaştırılması için de taş unu (kireçtaşı) kullanılarak kontrol betonları (KTU) üretilmiștir. Çalışmada Isparta-Karakaya pomzası ile üretilen köpük beton (IKP), Kayseri pomzası ile üretilen köpük beton (KP), Nevşehir pomzası ile üretilen köpük beton (NP) ve Karaman pomzası ile üretilen köpük beton ise (KMP) ile gösterilmiştir. Beton üretiminde bağlayıcı olarak Isparta Göltaş Çimento Fabrikası'ndan alınan Portland çimentosu (CEM I 42,5 R), karıșım suyu olarak ise Süleyman Demirel Üniversitesi Batı kampüsünde kullanılan şebeke suyu kullanılmıştır.

Köpük beton üretiminde agrega olarak kullanılan pomza türlerinin boyutları, tüm karıșımlarda 1-2 mm arasındadır. Kontrol betonu (KTU) için ise agrega yerine çok ince agrega olarak boyutu $0.1 \mathrm{~mm}(100$ $\mu$ )'den küçük taş unu (kireçtaşı) kullanılmıştır. Pomza agregalarının çalışmamızda gerekli olan etüv kurusu tane yoğunluğu ve su emme değerleri, TS EN 10976'ya (2013) uygun olarak piknometre metodu ile belirlenmiștir. Toplamda 5 karışım tasarımı hazırlanmış olup her bir karışım tasarımı için hedeflenen teorik kuru yoğunluklara göre, karıșıma girecek bileșen miktarları hacim yöntemi $\left(1 \mathrm{~m}^{3}\right)$ esas alınarak hesaplanmıştır. Tüm karışımlarda çimento dozajı ve su/katı $(\mathrm{s} / \mathrm{k})$ oranı $(0,45)$ sabit tutulmuştur. Ayrıca tüm karışımlarda köpük beton üretileceğinden köpük üretimi için eşit miktarda sentetik esaslı köpük ajanı kullanılmıștır. Tablo 1'de üretilen köpük betonların $1 \mathrm{~m}^{3}$ karışım için bileşen miktarları verilmiştir.

Tablo 1. Üretilen köpük betonların bileșen miktarları (1 m³ için)

\begin{tabular}{|c|c|c|c|c|c|}
\hline : & 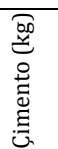 & 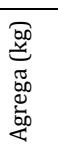 & 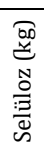 & 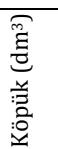 & $\begin{array}{l}\Xi \\
\vec{B}\end{array}$ \\
\hline IKP & 250 & 250 & 1 & 598 & 112,5 \\
\hline $\mathrm{KP}$ & 250 & 250 & 1 & 494 & 112,5 \\
\hline $\mathrm{NP}$ & 250 & 250 & 1 & 449 & 112,5 \\
\hline KMP & 250 & 250 & 1 & 598 & 112,5 \\
\hline KTU & 250 & 350 & 1 & 519 & 270 \\
\hline
\end{tabular}

Köpük betonların üretimi, SDÜ Doğal ve Endüstriyel Yapı Malzemeleri Araştırma ve Uygulama Merkezi nde yapılmıştır. Toplamda 5 seri köpük beton üretilmiștir ve numune kalıplarına yerleştirilmiștir. Numuneler, 24 saat kalıp içerisinde bırakılmıștır ve bu sürenin sonunda kalıptan çıkartılmıştır. Tüm deney numuneleri, 28 gün boyunca $20 \pm 2{ }^{\circ} \mathrm{C}$ sıcaklı̆̆ ve $\% 95$ bağll nemi olan kür havuzunda saklanmıştır. Üretilen köpük beton numuneleri Şekil 1 'de gösterilmiștir.

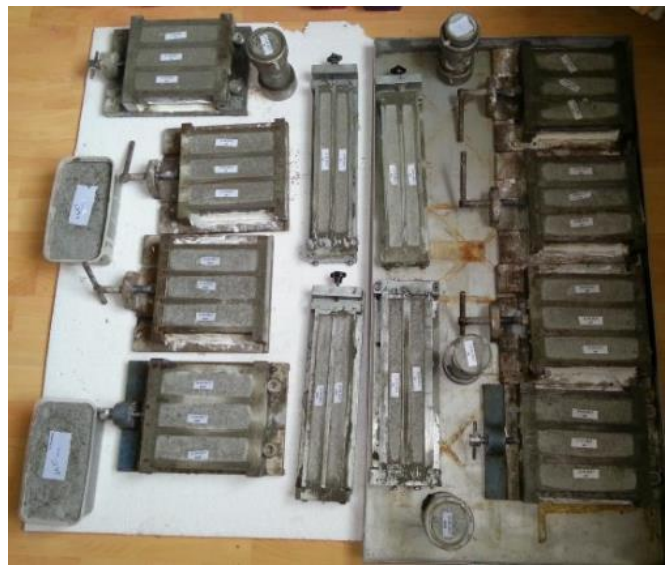

Şekil 1. Üretilen köpük beton numuneleri

Çalıșma kapsamında her bir seri için 5 adet $10 \times 10 \times 10$ cm'lik küp numune, 1 adet $63 \mathrm{~mm}$ çapında $25 \mathrm{~mm}$ kalınlığında silindir numune, 2 adet $29 \mathrm{~mm}$ çapında 50 $\mathrm{mm}$ kalınlığında silindir numune, 1 adet $100 \mathrm{~mm}$ çapında $20 \mathrm{~mm}$ kalınlığında silindir numune ve 1 adet $100 \mathrm{~mm}$ çapında $40 \mathrm{~mm}$ kalınlığında silindir numune üretilmiştir. Üretilen köpük betonlara sertleşmiş (28 gün) halde iken yoğunluk, basınç dayanımı, ısı iletkenlik, ses yutuculuk ve ses iletim kaybı deneyleri yapılmıştır.

Köpük betonların kuru yoğunlukları, TS EN 678 (1995) standardına göre elektronik kumpas ve hassas terazi yardımı ile bulunmuştur. Basınç dayanımı deneyi, tek eksenli basınç dayanımı test cihazı ile TS EN 1354'e (2007) göre yapılmıștır. Köpük betonların ısı iletkenlik deneyinde ısı akısı ölçme yöntemi ile çalışan Lasercomp Fox 50 isı iletkenlik cihazı kullanılmıștır. Isı iletkenlik deneyleri, TS EN 12664 (2009) ve TS EN 12667 (2003) standardları esas alınarak yapılmıștır. Köpük betonların ses yutuculuk ve ses iletim kaybı deneylerinde ise, empedans tüpü ölçüm yöntemi tercih edilmiştir. Empedans tüpü ölçüm metodu, akustik parametrelerden ses yutma katsayısı $(\propto)$ ve ses iletim kaybı (TL) ölçümüne olanak vermektedir. Ses yutma katsayısı $(\propto)$, ASTM-E 1050, TS EN ISO 10534-1 (2004) ve TS EN ISO 10534-2 (2003) standardlarına uygun olarak empedans tüpü ile bulunur. Söz konusu malzemenin ses yutma katsayı $(\propto)$, formülde belirtilen frekans değerlerine göre Denklem 1 yardımıyla ortalama olarak hesaplanır.

$\propto=\frac{\propto_{250}+\propto_{500}+\propto_{1000}+\propto_{2000}}{4}$ 
Önemli akustik parametrelerden bir diğeri olan ses iletim kaybı (TL) ise, ASTM-E 2611 standardına göre yine empedans tüpü ile bulunur ve birimi desibel (dB)'dir. Ses iletim kaybı (TL), standart frekans değerlerine göre Denklem 2 yardımıyla ortalama olarak hesaplanır.

$\mathrm{TL}=\frac{\mathrm{TL}_{63}+\mathrm{TL}_{85}+\ldots+\mathrm{TL}_{5000}+\mathrm{TL}_{6300}}{21}$

\section{Bulgular}

Deneysel çalışmada üretilen sertleşmiş köpük beton numuneleri için gerçekleșen kuru yoğunluk değerleri, TS EN 678 (1995) standardına göre belirlenmiş olup her seri için 2 adet küp numune deneye tabi tutulmuştur ve sonuçların ortalaması alınmıştır. Tablo 2'de sertleşmiş köpük beton numunelerinin teorik ve gerçek kuru yoğunluk değerleri verilmiștir.

Tablo 2. Köpük betonların kuru yoğunlukları $\left(\mathrm{kg} / \mathrm{m}^{3}\right)$

\begin{tabular}{|c|c|c|}
\hline \multirow{2}{*}{ Seri } & Teorik & Gerçek \\
\cline { 2 - 3 } & $\rho_{\mathrm{tk}}$ & $\rho_{\mathrm{gk}}$ \\
\hline IKP & 500 & 551 \\
\hline KP & 500 & 633 \\
\hline NP & 500 & 672 \\
\hline KMP & 500 & 463 \\
\hline KTU & 600 & 588 \\
\hline \multicolumn{2}{|c|}{$\rho_{\text {tk }}:$ Teorik kuru beton yoğunluğu $\left(\mathrm{kg} / \mathrm{m}^{3}\right)$} \\
\hline$\rho_{\text {gk }}:$ Gerçek kuru beton yoğunluğu $\left(\mathrm{kg} / \mathrm{m}^{3}\right)$ \\
\hline
\end{tabular}

Köpük betonların gerçek kuru yoğunlukları incelendiğinde, $463-672 \mathrm{~kg} / \mathrm{m}^{3}$ aralığında değişen değerler aldığı görülmektedir. En düşük değer (463 $\left.\mathrm{kg} / \mathrm{m}^{3}\right) \mathrm{KMP}$ serisine, en yüksek değer $\left(672 \mathrm{~kg} / \mathrm{m}^{3}\right)$ ise NP serisine aittir. IKP serisi $\left(551 \mathrm{~kg} / \mathrm{m}^{3}\right)$ ve KTU serisi $\left(588 \mathrm{~kg} / \mathrm{m}^{3}\right)$ birbirine yakın değerler almıştır. Aynı şekilde, KP $\left(633 \mathrm{~kg} / \mathrm{m}^{3}\right)$ ve NP $\left(672 \mathrm{~kg} / \mathrm{m}^{3}\right)$ serileri de birbirine yakındır. Ayrıca KP serisi, NP serisinden sonra en yüksek değeri almıştır.

Şekil 2'de 28 günlük sertleşmiş köpük beton numunelerinin gerçek kuru yoğunluk değerleri, grafik olarak gösterilmiștir.

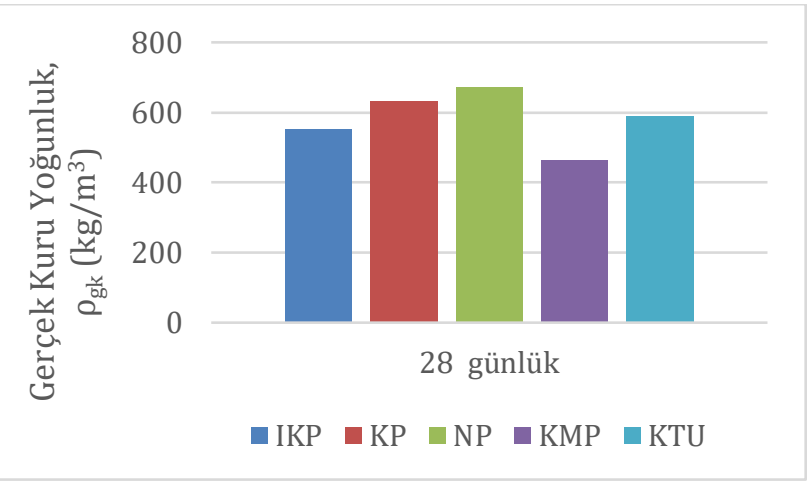

Şekil 2. Köpük betonların gerçek kuru yoğunlukları
Köpük betonların basınç dayanımı deneyinde, her seri için 2 adet küp numune deneye tabi tutulmuş olup sonuçların ortalaması alınmıştır. 28 günlük sertleşmiş köpük beton numunelerinin tek eksenli basınç dayanımı değerleri, Şekil 3'de verilmiştir. Köpük betonların basınç dayanımları incelendiğinde, 0,373,50 $\mathrm{MPa}$ aralığında değișen değerler aldığ görülmektedir. En düşük değer $(0,37 \mathrm{MPa}) \mathrm{KMP}$ serisine, en yüksek değer $(3,50 \mathrm{MPa})$ ise NP serisine aittir. IKP serisi $0,75 \mathrm{MPa}$, KTU serisi 1,40 MPa ve KP serisi ise 1,87 MPa değerini almıştır. KP ve KTU serileri birbirine yakındır.

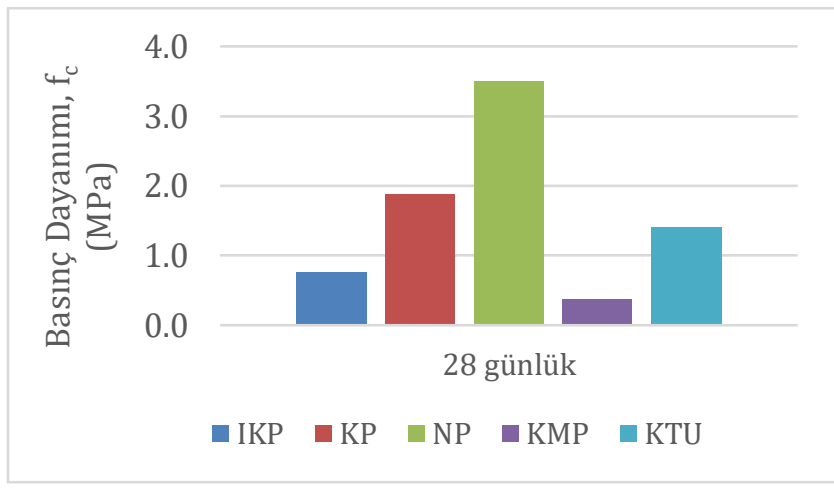

Şekil 3. Köpük betonların basınç dayanımları

Köpük betonların ısı iletkenlik deneyinde, her seri için $63 \mathrm{~mm}$ çapında $25 \mathrm{~mm}$ kalınlığında 1 adet silindir numune deneye tabi tutulmuştur. 28 günlük sertleşmiş köpük beton numunelerinin isı iletkenlik katsayıları (k), Şekil 4'de verilmiştir. Köpük betonların ISı iletkenlik katsayıları incelendiğinde, 0,121-0,177 $\mathrm{W} / \mathrm{mK}$ aralığında değişen değerler aldığ görülmektedir. En düşük değer $(0,121 \mathrm{~W} / \mathrm{mK}) \mathrm{KMP}$ serisine, en yüksek değer $(0,177 \mathrm{~W} / \mathrm{mK})$ ise KTU serisine aittir. IKP serisi $0,147 \mathrm{~W} / \mathrm{mK}$, KP serisi 0,147 $\mathrm{W} / \mathrm{mK}, \mathrm{NP}$ serisi $0,163 \mathrm{~W} / \mathrm{mK}$ değerini almıștır.

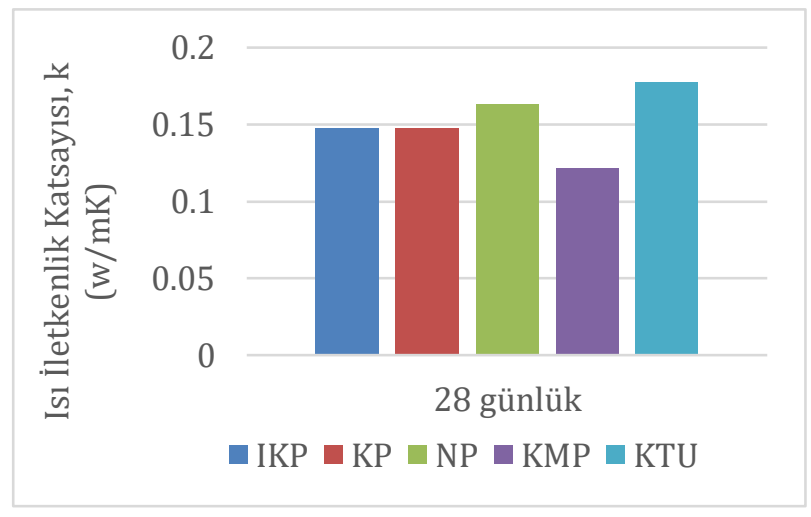

Şekil 4. Köpük betonların ısı iletkenlik katsayıları

Köpük betonların ses yutuculuk ve ses iletim kaybı deneylerinde; her seri için çapları $29 \mathrm{~mm}$ ve $100 \mathrm{~mm}$ olan numuneler, ses yutma katsayıları ve ses iletim kayıplarının ölçümü için empedans tüpü ile teste tabi tutulmuş ve sonuçların ortalaması alınmıştır. Köpük 
beton serilerinin $63-6300 \mathrm{~Hz}$ frekans aralığında elde edilen ses yutma katsayısı $(\propto)$ ve ses iletim kaybı (TL) değerleri, Tablo 3'de verilmiștir. Bu değerler, Denklem 1 ve Denklem 2 yardımıyla bulunmuştur.

Tablo 3. Köpük betonların ses yutma katsayısı ve ses iletim kaybı değerleri

\begin{tabular}{|c|c|c|}
\hline Seri & $\begin{array}{c}\text { Ses yutma } \\
\text { katsayıs }\end{array}$ & $\begin{array}{c}\text { Ses iletim } \\
\text { kaybi (dB) }\end{array}$ \\
\hline IKP & 0,27 & 5,1 \\
\hline KP & 0,44 & 10,3 \\
\hline NP & 0,35 & 7,5 \\
\hline KMP & 0,36 & 5,0 \\
\hline KTU & 0,31 & 14,2 \\
\hline
\end{tabular}

Köpük betonların 63-6300 Hz aralığındaki ortalama ses yutma katsayıları incelendiğinde, 0,27-0,44 aralığında değișen değerler aldığı görülmektedir. En düşük değer $(0,27)$ IKP serisine, en yüksek değer $(0,44)$ ise KP serisine aittir. KTU serisi 0,31 , NP serisi 0,35, KMP serisi 0,36 değerini almıştır. Köpük betonların 63-6300 $\mathrm{Hz}$ aralığındaki ortalama ses iletim kayıpları incelendiğinde, 5,0-14,2 dB aralığında değişen değerler aldığı görülmektedir. En düșük değer $(5,0 \mathrm{~dB}) \mathrm{KMP}$ serisine, en yüksek değer $(14,2 \mathrm{~dB})$ ise KTU serisine aittir. IKP serisi 5,1 dB, NP serisi 7,5 dB, KP serisi 10,3 dB değerini almıștır. IKP ve KMP serileri, birbirine yakındır. KP serisi ise, KTU serisinden sonra en yüksek değeri almıştır.

\section{Sonuç ve Öneriler}

$\mathrm{Bu}$ çalışmada ülkemizde potansiyeli yüksek olan pomza çeşitlerinden Isparta pomzası, Kayseri pomzası, Nevşehir pomzası ve Karaman pomzası kullanılarak 4 farklı pomza agregalı köpük beton üretilmiştir. Ayrıca taş unu (kireçtaşı) kullanılarak da kontrol köpük beton üretimi yapılmıştır. Tüm serilerde su/katı oranı ve çimento dozajı sabit olacak şekilde üretim yapılmıș ve elde edilen köpük betonların yoğunluk, basınç dayanımı, ısı iletkenlik katsayısı, ses yutma katsayısı ve ses iletim kaybı değerleri karşılaştırılmıștır. Böylelikle kullanılan pomza türünün, köpük betonun özelliklerine etkisi araştırılmıştır. Çalışmada elde edilen bulguların toplu olarak değerlendirilmesi neticesinde çıkarılacak bazı sonuç ve öneriler aşağıda özetlenmiştir.

Köpük betonların basınç dayanım değerleri, gerçek kuru yoğunluk değerleriyle benzerlik göstermiştir. Köpük betonların basınç dayanımları incelendiğinde; gerçek kuru yoğunluk değerlerinde olduğu gibi en düşük değer yine KMP serisine, en yüksek değer yine NP serisine ait olup KP serisi ise NP serisinden sonra yine en yüksek değeri almıştır.
Köpük betonlardan KTU serisi, ses iletim kaybı parametresinde en iyi sonucu vermiştir. KTU serisinin basınç dayanımı değeri, kabul edilebilir düzeydedir. KTU serisinin dezavantajları ise, Isı iletkenlik katsayısının yüksek ve ses yutma katsayısının düşük olmasidır.

NP serisi, ısı iletkenlik katsayısı ve ses iletim kaybı parametrelerinde uygun sonuçlar vermemiştir. NP serisinin avantajı ise, basınç dayanımının yüksek olmasidır.

KP serisi incelendiğinde, tüm parametreler için uygun sonuçlar verdiği görülmektedir. Dolayısıyla KP ve NP serileri birbiriyle kiyaslandığında incelenen özelliklerinin, KP serisinin NP serisinden basınç dayanımı dışında daha iyi olduğu söylenebilir.

KMP serisi, ısı iletkenlik katsayısı parametresinde en iyi sonucu vermiştir. KMP serisinin ses yutma katsayısı ise, kabul edilebilir düzeydedir. KMP serisinin dezavantajları ise, basınç dayanımının ve ses iletim kaybının çok düşük olmasıdır.

IKP serisi ise, ısı iletkenlik katsayısı dışındaki diğer parametrelerde uygun sonuçlar vermemiştir. Dolayısiyla IKP ve KMP serileri birbiriyle kıyaslandığında, KMP serisinin IKP serisinden daha üstün olduğu söylenebilir.

Pomza kökeninin incelenen özellikler üzerinde farklılık gösterdiği gözlenmiştir. Bunun sebebi pomzanın gözenekli bir yapıya sahip olması ve bu incelenen özelliklerinin pomzanın yapısı ile ilişkili olmasidır.

Enerji kaynakları açısından önemli ölçüde dışa bağımlı olan ülkemizde üzerinde ayrıntılı çalışma yapılmamış birçok pomza yatağı mevcuttur. Isparta, Kayseri, Nevşehir ve Karaman pomzaları dışındaki diğer türlerle ilgili çalışmalar yapılmalıdır. $\mathrm{Bu}$ tür çalışmalarla, özellikle ısı ve ses yalıtımı açısından en uygun pomza türü belirlenmiş olacaktır. Ayrıca bu tür çalışmalar sonucunda, ülkemizde potansiyeli yüksek olan bu doğal kaynakların teknik bir envanteri de çıkarılmış olacaktır.

\section{Teşekkür}

4855-YL1-17 No 'lu Proje ile çalıșmamızı maddi olarak destekleyen Süleyman Demirel Üniversitesi Bilimsel Araştırma Projeleri Yönetim Birimi Başkanlığı'na teşekkür ederiz.

\section{Çıkar Çatışması}

Yazarlar tarafından herhangi bir çıkar çatışması beyan 
edilmemiştir.

\section{Kaynaklar}

ASTM-E 1050, 2006. International Standard: Standard Test Method for Impedance and Absorption of Acoustical Materials Using A Tube, Two Microphones and A Digital Frequency Analysis System.

ASTM-E 2611, 2006. Standard Test Method for Measurement of Normal Incidence Sound Transmission of Acoustical Materials Based on the Transfer Matrix Method. New York, USA.

Baradan, B., 1991. Yapı Malzemesi-II. Dokuz Eylül Üniveritesi Mühendislik- Mimarlık Fakültesi yayını, s 1-3, İzmir.

Davraz, M., 2001. Pomzanın Endrüstriyel Kullanım Alanları. Süleyman Demirel Üniversitesi, Fen Bilimleri Enstitüsü, Doktora Semineri, Isparta.

Davraz, M., Kılınçarslan, Ş., Koru, M., 2015. Farklı yoğunluktaki köpük betonların dayanım ve ısıl iletkenlik özellikleri, 9. Ulusal beton kongresi, (2015), 93-102.

Eriç, M., 2002. Yapı Fiziği ve Malzemesi, Literatür Yayınevi, İstanbul.

Ekinci, D., 2013. Türkiye'de köpük beton. Dünya İnşaatDergisi.

http://www.dunyainsaat.com.tr/dergioku.php?ha berid $=4224$.

Konuk, H., Özyurt, N., Taşdemir, C., Yüceer, Z., Sönmez, R., 2002. Hafif betonların taşıyıcılık özellikleri, 1. Ulusal Yapı Malzemesi Kongresi, İstanbul.

Neville, A.M., 1975. Properties of Concrete. Pitman Publishing. London.

Neville, A.M., and Brooks, J.J., 1987. Concrete Tecnology. Longman Scientific and Tecnical, 155.

TS EN 678, 1995. Gaz ve köpük beton-Kuru yoğunluk tayini. TSE, Ankara.

TS EN 1354, 2007. Gözenekli hafif beton - Basınç dayanımının tayini. TSE, Ankara.

TS EN 12667, 2003. Yapı malzemeleri ve mamullerinin ısıl performansı-Mahfazalı sıcak plaka ve ısı akış sayacı metotlarıyla ısıl direncin tayini-Yüksek ve orta ısıl dirençli mamuller. TSE, Ankara.

TS EN 12664, 2009. Yapı malzemeleri ve mamulleri Isıl direncin, korumalı tablalı ısıtıcı ve isı akı ölçerin kullanıldığı metotlarla tayini - Isıl direnci orta ve düşük seviyede olan kuru ve rutubetli mamuller. TSE, Ankara.
TS EN 1097-6, 2013. Agregaların mekanik ve fiziksel özellikleri için deneyler - Bölüm 6: Tane yoğunluğunun ve su emme oranının tayini. TSE, Ankara.

TS EN ISO 10534-1, 2004. Akustik- Empedans borularında ses absorplama katsayısı ve empedansın tayini - Bölüm 1: Duran dalga oranını kullanma metodu. TSE, Ankara.

TS EN ISO 10534-2, 2003. Akustik-Empedans borularındaki ses absorpsiyon katsayısının ve empedansın tayini-Bölüm 2: Aktarım fonksiyonu metodu. TSE, Ankara.

Uluata, A.R., 1981. Beton Malzemeleri ve Beton, Atatürk Üniversitesi Ziraat Fakültesi Yayını, Erzurum. 